Running head: GENDER STEREOTYPES AND ACADEMIC ACHIEVEMENT

The Hidden Classroom: How Gender Stereotypes Impact Academic Achievement

\author{
Antonya Marie Gonzalez ${ }^{1}$ \\ Hee Jae Julie $\mathrm{Oh}^{2}$ \\ Andrew Scott Baron ${ }^{3}$ \\ ${ }^{1}$ Western Washington University \\ ${ }^{2}$ McGill University \\ ${ }^{3}$ University of British Columbia
}

\begin{abstract}
Author Note:
This manuscript is a pre-print of an invited book chapter to be published in the Cambridge Handbook of Applied School Psychology. This manuscript is not the copy of record and therefore will not replicate the final, authoritative version of the manuscript.
\end{abstract}




\section{The Hidden Classroom: How Gender Stereotypes Impact Academic Achievement}

Advancements in science, technology, engineering, and mathematics, otherwise known as STEM fields, play a critical role in social improvement and economic expansion. Accordingly, opportunities for jobs in these fields have grown rapidly, and are projected to continue growing over the next decade (Economics and Statistics Administration, 2017). Recognizing the extraordinary challenge of preparing the next generation of children to contribute to this growing need, both state and federal departments of education have increased focus (and spending) on STEM curricula, including more standardized testing in science and math beginning in early elementary school (Common Core State Standard Initiative, 2016; National Research Council, 2012). As countries strive to compete in these fields, researchers have identified a critical shortcoming: the underrepresentation of women in STEM fields (National Science Foundation, 2014; Organization for Economic Cooperation and Development, 2012). Though women comprise over $50 \%$ of college educated workers, they only make up a quarter of college educated STEM workers (Economics and Statistics Administration, 2017). Furthermore, there is severe underrepresentation of women in certain STEM fields; computer science and engineering are composed of less than 20\% women at all levels (National Science Foundation, 2017).

Gender divergence in STEM interest and performance begins even before men and women make crucial career decisions in adulthood, with high school and college girls underperforming and showing less interest in STEM. On average, high school boys score 30 points higher than girls on the math section of the Standard Admissions Test for college (College Board, 2016). This gap continues when students enter university, with more young men enrolling in STEM courses than young women (de Cohen \& Deterding, 2009; Statistics Canada, 2011). By 
graduation, only $30 \%$ of undergraduate degree holders in STEM fields are women (Economic \& Statistics Administration, 2017).

As psychologists and as educators, it is crucial to understand the developmental antecedents and causes of this notable gender imbalance. Evidence suggests that the origins of a gender disparity in STEM are rooted in early childhood (Ceci \& Williams, 2011). Indeed, children's STEM trajectory begins in elementary school, when they first begin placing into math courses based on performance (Fong \& Finkelstein, 2014). Better math performance results in a more accelerated trajectory, allowing children to progress to advanced math and science (e.g., Calculus, Physics) in high school. This early placement is one of the initial points where girls may turn away from STEM careers by opting out of foundational courses for entering these fields (Valla \& Williams, 2012). Notably, even when these decisions appear to be made based on individual interest rather than performance, they are not independent decisions; as we detail further in this chapter, academic choices are constrained by social expectations in childhood such as how well girls see themselves conforming to gender stereotypes (e.g. Cheryan, Master, \& Meltzoff, 2015; Eccles, 2011).

In this chapter, we aim to document a key psychological factor influencing children's achievement in STEM: gender stereotypes. Specifically, we focus on the development of gender stereotypes about math ability and interest, as well as the consequences of these biases for math engagement and performance in the classroom. We detail the effects of explicit, or consciously accessible stereotypes, which are easily transmitted through verbal expression. Furthermore, we recognize that such gender stereotypes can fester beneath the surface, at a more unconscious level, in the form of implicit stereotypes. As these stereotypes have been shown to affect children's association between themselves and math (also known as math self-concept) as well as their performance on math assessments, we also review their effects here. Because gender 
stereotypes can be subtle, and in the case of implicit stereotypes, are often unbeknownst to the self and to others, we refer to the environment of impact as "the hidden classroom." After exploring the sources of these explicit and implicit biases in childhood, we will outline key directions for reshaping STEM-related stereotypes and developing methods to buffer children from the negative effects of stereotypes on classroom performance. In sum, the goal of this chapter is to communicate potential ways to chip away at a critical psychological barrier to girls' pursuit of STEM careers.

\section{Gender Stereotypes and their Impact in Childhood}

Explicit Gender Stereotypes. Much of the initial work on children's beliefs about gender and math has focused on measuring their explicit, consciously accessible, attitudes and stereotypes. Several studies have found that children as young as age five explicitly endorse traditional stereotypes associating math more strongly with boys than girls (see Régner, Steele, Ambady, Thinus-Blanc, \& Huguet, 2014 for a review). For example, in a study conducted in the U.S. and Japan, Lummis and Stevenson (1990) found that children and their parents endorse the stereotype that girls are better at reading and boys are better at math. This result is consistent with other cross-cultural work conducted in Chile showing that children believe girls dislike math, find it to be harder, and are worse at it in comparison to language arts (del Río \& Strasser, 2013). Collectively, this work demonstrates that the seeds of this stereotype have already begun to lay roots in the minds of young children just as they are about to embark on formal schooling (see also Cvencek, Meltzoff, \& Greenwald, 2011; Cvencek, Meltzoff, \& Kapur, 2014).

As children get older, they learn in many cultures that it is not socially acceptable to express social stereotypes. A consequence of this learning, and perhaps from increasing executive control, is that children appear to become less biased across development on explicit measures of bias (Baron, 2015; Raabe \& Beelmann, 2011). However, ample studies with adults 
shows us that such implicit biases persist and influence behavior even when our explicit measures of bias suggest otherwise (Greenwald, Poehlman, Uhlmann, \& Banaji, 2009). To avoid these self-presentation concerns, researchers have looked to implicit measures of bias because they are much more difficult to fake. Furthermore, implicit associations are typically insensitive to social norms restricting the expression of bias, and crucially, among adults, implicit bias is directly linked to performance and interest in STEM (e.g. Cao \& Banaji, 2016; Kiefer \& Sekaquaptewa, 2007; Schmader, Johns, \& Barquissau, 2004). Thus, in order to gain a comprehensive understanding of the development of gender stereotypes, researchers must examine both explicit and implicit forms of bias.

Implicit Gender Stereotypes. Studies have recently shown that children have implicit stereotypes about gender and academics that are comparable to those of adult populations (Cvencek et al., 2011; 2014; Cvencek, Kapur, \& Meltzoff, 2015; Passolunghi, Rueda Ferreira, \& Tomasetto, 2014). In one of the first studies to examine children's implicit math-gender stereotypes, researchers tested a sample of children between 6-10 years of age (Cvencek et al., 2011). Implicit stereotypes were measured using a child-friendly version of the Implicit Association Test (IAT; see Baron \& Banaji, 2006 for further details). This test measures unconscious stereotypes by testing how quickly children categorize words and images when two categories are paired on the same side of a keyboard. For example, on one set of test trials, children must categorize words and images when the category labels of "boy" and "math" are on the same side (and "girl" and "reading" are on the opposite side). For the second set of trials, they must categorize words and images when "girl" and "math" are on the same side (with "boy" and "reading" on the opposite side). If children are faster (and more accurate) to respond when the category labels "boy" and "math" share the same key, then this suggests a stronger implicit association between these concepts. Indeed, results of this study indicated that boys and girls 
implicitly associated boys more with math, and girls more with reading (Cvencek et al., 2011). Thus, as young as age six, children have automatic associations between gender and math that are consistent with the broader cultural stereotype, even though explicitly, they may not always express this belief (Régner et al., 2014).

In another study, researchers examined whether Singaporean elementary school aged children (ages 7-11) had implicit stereotypes associating math more with boys (Cvencek et al., 2014). Singapore is a particularly interesting case, as children in Singapore excel in mathematics, and young girls in this country actually outperform boys on math assessments, such as the Trends in International Mathematics and Science Study (TIMSS; Mullis, Martin, Foy, \& Arora, 2011). However, Singaporean boys and girls still implicitly associated math more with boys, indicating that these stereotypes are pervasive, regardless of actual gendered performance in these domains.

These results have been replicated cross-culturally, underscoring the prevalence of this stereotype in children of this age (Cvencek et al., 2014; Passolunghi et al., 2014; Steffens, Jelenec, \& Noack, 2010). For example, in a study of children's implicit math-gender stereotypes, Passolunghi et al. (2014) found that Italian girls as young as seven had an implicit stereotype associating math more with boys, while boys did not have this stereotype until around age thirteen. This result is consistent with a study conducted in Germany where girls as young as nine years old implicitly associated math more with boys, but boys at this age did not have this stereotype (Steffens et al., 2010). Thus, while there might be some variability in when children acquire implicit gender stereotypes, girls appear to internalize them as early as age six or seven.

Stereotypes shape academic choices. In addition to demonstrating the presence of explicit and implicit gender-math stereotypes in early childhood, research indicates that these stereotypes often shape children's academic beliefs and interests. For example, studies have 
shown that as early as age six, young boys are more likely than girls to believe that members of their gender are brilliant (Bian, Leslie, \& Cimpian, 2017). Furthermore, these beliefs actually affect children's choices and lead young girls to avoid activities associated with brilliance. Thus, in very early elementary school, girls already hold beliefs about their own capabilities, and these beliefs constrain their academic choices.

Related findings have shown that girls at this age who associate STEM with boys express less academic interest in STEM fields (Cheryan, Plaut, Handron, \& Hudson, 2013; Master, Cheryan, \& Meltzoff, 2016; Shapiro \& Williams, 2012). For example, girls who believe boys are better at robotics and programming express less interest and self-efficacy in those domains (Master, Cheryan, Moscatelli, \& Meltzoff, 2017). More generally speaking, research has shown that girls in this age range express less interest and self-confidence in science and technology domains (Cheryan et al., 2013; Beghetto, 2007; McKenney \& Voogt, 2010).

Another way in which stereotypes about gender and math-related fields affect girls' academic choices is by leading them to ascribe less value to math-related domains (Eccles et al., 1983). According to Eccles's expectancy value hypothesis, academic and career choices are influenced by the value that one attaches to each domain (Eccles \& Wang, 2016). Thus, viewing math-related fields as less valuable or important can result in girls' decreased interest in pursuing achievement in those areas. For example, gender differences in junior high school students' decisions to enroll in advanced mathematics courses are mediated by gender differences in the value students attach to math, indicating that girls are less likely to enroll in these courses because they feel math is less interesting and enjoyable (Eccles, Adler, \& Meece, 1984). As traditional math-gender stereotypes can lead girls to value math less, it is theorized that girls who have internalized these stereotypes may spend less time studying or striving to excel in those courses (Steffens et al., 2010). 
Stereotypes can also reduce girls' interest in math-related domains by impacting their sense of belonging in those fields; specifically, how much they feel they would fit in with the people, materials, and activities in a STEM environment (Cheryan, Plaut, Davies, \& Steele, 2009). In a study by Master et al. (2016), adolescent girls ages 14-18 were more likely to express interest in computer science courses if classroom settings did not reflect masculine computer science stereotypes. This finding is similar to work by Cheryan and colleagues (2013) that showed that adult women's interest in computer science was influenced by how much they felt they fit personally with stereotypes about computer science, suggesting that across most of development women and girls' interest in STEM can be influenced by the gender-inclusive messages they receive about STEM in their environment. In sum, gender stereotypes can affect girls' academic interest through subtle environmental cues, as well as more overtly influencing girls' valuation of and interest in math-related domains.

Stereotypes shape academic performance. In addition to shaping academic interests, gender stereotypes can affect academic performance across development. A number of studies have found that adult women's math performance can be impacted through contextual cues that remind them of stereotypes about math and gender (e.g. Ambady, Paik, Steele, Owen-Smith, \& Mitchell, 2004; Beilock, Rydell, \& McConnell, 2007; Schmader \& Johns, 2003; Spencer, Steele, \& Quinn, 1999), as well as even subtler cues, such as asking about gender before a math test (e.g., Danaher \& Crandall, 2008; Stricker \& Ward, 2004). Building off this work with adults, Ambady and colleagues (2001) examined whether contextually activating the gender identity of girls ages 5-13 would remind them of gender stereotypes, and consequently, impair math performance. As compared to girls in a control condition (who colored neutral images), younger and older girls who colored images designed to prime gender identity performed worse on a 
standardized math test: indicating that they had internalized gender stereotypes and were negatively affected when these stereotypes were activated.

In a conceptual replication of this effect, researchers presented girls with one of two images to color; one where a girl was correctly solving a math problem while a boy failed to solve it, and one where a boy correctly solved the problem and the girl failed (Galdi, Cadinu, \& Tomasetto, 2014). As compared to the counter-stereotypical coloring task, after exposure to the stereotypic coloring task, girls did significantly worse on a math assessment. Similar effects have been found in other studies with girls as young as age five, demonstrating that stereotype-based performance effects can emerge relatively early in development (e.g. Muzzatti \& Agnoli, 2007; Tomasetto, Alparone, \& Cadinu, 2011). Thus, researchers and educators must consider intervening in early elementary school, as performance impairments at this age will affect children's later placement into STEM-related courses.

\section{Sources of Gender Stereotypes}

Children's acquisition of stereotypes about gender and academics are influenced by a variety of sources, both in and outside of the school environment. Here, we examine several such prominent sources.

Social role distribution. Social role theory posits that gender stereotypes reflect observations of existing divisions of behavior. Consistent with this idea, research with adults reveals that the strength of implicit and explicit math-gender stereotypes is related to the distribution of men and women in math-related fields (Eagly \& Steffens, 1984; Cao \& Banaji, 2016). In one set of studies, when participants were presented with a novel woman or man, they tended to assume both implicitly and explicitly that the man was in a career with a higher base rate of men (e.g. doctor) and that the woman was in a career with a higher base rate of women (e.g. nurse). These results support the hypothesis that base rate distributions are a source of bias. 
These distributions also impact the pursuit of STEM related careers. For example, Stearns and colleagues (2016) found that young women were more likely to pursue math-related majors in college if they had previously attended schools with a higher proportion of women math and science teachers. This is also reflected in high school levels of STEM engagement, as female teachers' representation in STEM influences girls' math achievement and pursuit of STEM careers (Bottia, Stearns, Mickelson, Moller, \& Parker, 2015).

Media exposure. Media sources, such as film, television, video games, and the internet, also play a role in creating and perpetuating gender stereotypes about STEM fields. Research by Smith and colleagues (2002) and found that only $21 \%$ of primetime television characters with STEM careers were women. Even within child friendly media, there is a representational imbalance, with far less women than men depicted in STEM careers; this number was even lower for children's movies (rated PG or below), with women representing less than a fifth of depicted characters in STEM-related roles. This biased exposure further conveys the message that STEM careers are generally held by men, adding to the effects of de facto social role distribution (Eagly \& Steffen, 1984).

Studies have also shown a causal link between media exposure and women's interest in STEM. In a study conducted with college women, Davies and colleagues (2002) found that after watching commercials that portrayed women as stereotypically domestic, participants had less interest in math-related education and career opportunities. These participants also performed worse on a subsequent math assessment, suggesting that such media exposure can shape math performance in a stereotype congruent fashion. Similarly, women's decreased interest in STEM careers is also attributed to media portrayals of STEM professionals who have characteristics that are inconsistent with women's gender roles (Cheryan et al., 2013). For example, the media often depicts computer scientists as socially inept and technology centered (e.g. Big Bang 
Theory, Silicon Valley; see Cheryan et al., 2015). This type of portrayal may result in women and girls feeling that they do not belong in STEM careers, and further perpetuates a stereotype that STEM is a better fit for men.

Educators and caregivers. Teachers and parents represent another critical influence on developing gender stereotypes, particularly through indirect transmission of their own biases. In a study of over 6,000 junior high school students (grades 6-8) in Switzerland, researchers found that teachers who explicitly stereotyped math as a domain for men were more likely to have students who also held this belief (Keller, 2001). Other work supports this finding; elementary school teachers who hold gender stereotypes about math believe that lower achieving boys are more competent in this domain than lower achieving girls (Tiedemann, 2000). Similarly, parents can also transmit stereotypes about math and gender; caregiver beliefs about gender and math ability are related to lower levels of math confidence in girls (Eccles \& Jacobs, 1986; Parsons, Adler, \& Kaczala, 1982). While the aforementioned studies do not identify a causal link between teachers' (or caregivers') own stereotypes and students' performance in the classroom, other research has shown that teachers' interactions with students are shaped by the gender stereotypes endorsed by the teacher. Specifically, recent work has shown that teachers with stronger traditional math-gender stereotypes are more likely to recommend boys to math/science-oriented programs (Nürnberger, Nerb, Schmitz, Keller, \& Sutterlin, 2015).

Another way that parents and teachers transmit stereotypes about STEM is through their own behavior and performance in those domains. For example, the attitudes women teachers have about math can be transmitted to their students, and consequently shape those students' stereotypes about math and gender (see Gunderson, Ramirez, Levine, \& Beilock, 2012 for a review). Specifically, when women role models hold negative attitudes about math, they may convey to young girls that math is not a subject where women succeed. For example, Beilock 
and colleagues (2010) found that even after controlling for first and second grades girls' math performance at the beginning of the year, higher levels of math anxiety in women teachers were associated with a) stronger gender stereotypes associating boys with math in students and b) lower math achievement for girls at the end of the year. The researchers hypothesized that high levels of math anxiety may impact the teaching styles of women teachers and lead them to be less interested or motivated in the teaching of math material. As a result, women teachers who are generally more math anxious may convey a lack of interest or ability in math, reinforcing girls' stereotypes about math and gender.

Transmission of stereotypes through math anxiety can also occur within the home. In a study by Maloney et al. (2015), parent's math anxiety predicted their children's math achievement; parents with higher math anxiety had children who performed worse in math at the end of the school year. Importantly, this only occurred if parents provided frequent help with math homework, and therefore had the opportunity to convey their math anxiety to children. This relationship was most robust in mother and daughter dyads, suggesting that young girls may be particularly sensitive to their mother's math anxiety as a cue to their own abilities in mathematics.

\section{Interventions to Increase Girls' STEM Engagement}

As detailed above, gender stereotypes can harm young girls by decreasing their interest and performance in STEM courses. Unfortunately, research suggests that prevention of these stereotypes is quite difficult, as children acquire stereotypes rapidly, and from relatively little input (Dunham, Baron, \& Carey, 2011; Gonzalez, Dunlop, \& Baron, 2017). While it may be difficult to limit all the forms of cultural messages that associate math more with boys than girls, there are ways to continuously counteract these stereotypes. In this section, we document two broad strategies for reducing the impact of gender stereotypes across development. 
To increase the number of girls who choose to pursue STEM fields, researchers and educators must introduce changes in the learning environment both inside and outside the classroom. To begin, it will be imperative to develop interventions to protect girls from the internalization of stereotypes suggesting women are less able than men to excel in STEM fields. This work can begin by focusing on changing the content of those stereotypes. Second, it will be imperative to develop interventions that help reduce the consequences of negative gender stereotypes for girls. In short, even if girls do internalize these nefarious stereotypes, it may be possible to disrupt the influence of those beliefs on their school engagement and performance (e.g., reducing their susceptibility to stereotype threat).

\section{Changing Gender Stereotypes}

Counter-stereotypical exemplar exposure. One effective strategy for changing children's gender stereotypes involves exposing children to counter-stereotypical exemplars. Gonzalez, Steele, and Baron (2017) found that exposing majority race (White and Asian) children to counter-stereotypical Black exemplars reduced implicit bias in children ages 9-12, but not among younger children ages 5-8. Children were read four short vignettes about positive Black exemplars within their community, and subsequently, their implicit pro-White, anti-Black bias was reduced. Though this study examined racial bias rather than gender stereotypes, these results indicate that late childhood might be an optimal time to target implicit bias.

Using a similar intervention strategy, Block and colleagues (under review) recently extended this work by examining implicit gender stereotypes following exposure to counter stereotypical exemplars with children ages 7-10. Children in this study were exposed to vignettes of either stereotypical exemplars (i.e. boys who like math, girls who like reading) or counterstereotypical exemplars (i.e. girls who like math, boys who like reading). Results indicated that unlike the children in the stereotypical condition, children who were exposed to counter- 
stereotypical exemplars no longer implicitly associated math with either boys or girls. This work suggests that brief exposure to exemplars can change implicit stereotypes, which are promising results for the use of counter-stereotypical exemplar-based interventions in home and school environments.

To translate these laboratory studies into practical strategies, educators and parents could create opportunities for children to learn about girls and boys who pursue counter-stereotypical domains. Parents might want to show their children TV shows and movies that depict girls and women engaged in STEM activities (e.g. Annedroids, SciGirls). Furthermore, parents can seek out child-friendly books that have more representation of women and girls in STEM roles (e.g. GoldieBlox, STEM Girls Book series). Educators can intervene in similar ways; when selecting media for one's classroom, they should attend to the representation of women, as well as possible perpetuation of stereotypes about whether women belong in STEM fields (e.g. having gender balanced exemplars in textbooks). Children could also be exposed to more women exemplars in STEM through in-person meetings (e.g. a Career Day expo, where children meet women in different STEM careers; Meet-A-Scientist, where woman scientists explain scientific phenomena to children; Science Camps). To counterbalance the overrepresentation of men in STEM fields, elementary and high school educators can spend more time teaching students about women scientists and mathematicians. High schools can also try to remedy this imbalance by actively seeking to hire more women teachers for science and math courses.

Reducing transmission of stereotypes. Parents and educators can also help reduce transmission of gender stereotypes by becoming aware of their own biases. Understanding one's own stereotypes about math and gender and attitudes toward math and science can help adults to recognize that they may be unintentionally conveying biased messages to children. To turn this knowledge into practice, parents and educators should be particularly attentive to how they speak 
to children about STEM. Studies have shown that parents are more likely to engage boys in conversations about science than girls; a behavior that promotes the belief that science is for boys (Crowley, Callanan, Tenenbaum, \& Allen, 2001). For example, in a study of families attending a local science museum, researchers found that while being equally likely to engage with sons and daughters, parents were three times more likely to explain the science behind the exhibits to their sons. Thus, adults should make note of how they speak to boys and girls about these topics to help ensure their own (implicit) biases are not inadvertently seeping through.

There are also a number of steps that parents and educators can take to try and avoid the transmission of stereotypes through math anxiety. Specifically, schools should consider providing options for additional mathematics training and confidence building. Much like exposure-based therapy, exposure to mathematics in the form of intensive tutoring sessions has been shown to decrease math anxiety (Supekar, Iuculano, Chen, \& Menon, 2015). Researchers have found that after an eight-week one-on-one tutoring program focusing on math strategies, math anxious children showed less of a fear response on neurological scans. Schools could apply this method to training with math anxious teachers and facilitate intensive mathematics workshops to try and ameliorate teacher anxiety.

Parents who have math anxiety could consider relearning some of the math skills that their children are currently learning or use an app/workbook with guided math problems that lead parents and children through the solution steps (e.g. Bedtime Math). A recent study with math anxious parents found that use of a math guided application at home with their first-grade children improved math achievement over the course of the school year (Berkowitz et al., 2015). Using apps or guided workbooks allows parents to focus less on knowing the math behind the provided problems, and more on learning the material with their child without the pressure of a homework or testing situation. 


\section{Disrupting the Impact of Stereotypes on Behavior}

Whereas the intervention strategies discussed above target the content of children's stereotypes, other intervention strategies could focus on disrupting the influence of these negative stereotypes on girls' engagement and performance in STEM.

Cultivating a STEM identity. One potential strategy is the cultivation of an identity associated with STEM domains. Master, Cheryan, \& Meltzoff (2017) found that assigning children to a group associated with either a math or spatial task increased preschoolers' STEM engagement. Children were assigned to either a group associated with a STEM-related task (e.g. the puzzle group) or labeled as an individual associated with a STEM-related task (e.g. the one who does puzzles). Assignment to a group increased children's time and effort spent on the task, potentially due to the power of membership in a group increasing children's motivation. This work is promising, as it suggests that creating a group identity for children has the potential to improve their STEM engagement.

Classroom interventions could therefore focus on building and reinforcing positive identities associated with math and science in an effort to increase girls' STEM engagement without directly changing the content of their implicit gender stereotypes. Fostering novel identities in early childhood that are positively associated with STEM, and activating these identities in test contexts, might facilitate more engagement and improved performance in these domains. This strategy could be readily employed in an elementary or high school classroom; teachers could work to cultivate a novel identity for the class (e.g., establishing math work groups with names) and associate this identity with math or science achievement. For example, work groups could be asked to come up with a name related to mathematics success (e.g. Number Ninjas). Teachers could activate this identity to potentially improve children's performance by asking students to get into their groups during critical learning or having them 
write their group name on assessments. Ideally, to solidify this identity over time, this intervention could be implemented at a school-wide level, with students maintaining their identities over the course of several years. However, even when established for a shorter time period at a classroom level, this exercise would still be worthwhile.

Reappraisal of test anxiety. Another way that stereotypes affect math performance is by limiting an individuals' ability to process information in working memory (Schmader \& Johns, 2003). In a study with adult women, researchers found that when primed with stereotypes about math ability, participants did worse on a task involving recall of new words. Studies with adults suggest that it may be possible to buffer women from these effects on performance through reappraisal of their anxiety (Johns, Inzlicht, \& Schmader, 2008). When women's high anxiety before a test is described to them as confidence rather than doubt, their performance is no longer impaired (Schmader, Forbes, Zhang, \& Mendes, 2009). Based on this method, this intervention could be applied in a classroom setting for children by instilling them with confidence before a math or science exam. For example, before taking a test, children could be instructed to read a short paragraph or write a short prompt about confidence in mathematics. This could take the form of reading about another child's confidence in math or writing about their own experiences.

Another approach could involve explicitly training children to view their anxiety as normative (Johns et al., 2008). Indeed, in a study with adults, participants who were told that anxiety could actually help their performance did better on a memory task than participants who were not given these reappraisal instructions. To adapt this method with children, teachers could spend some time in class teaching girls and boys that anxiety before tests is normal, can be helpful, and that they should try and channel their energy into excitement.

Eliminating gender stereotype cues. A final recommendation reviewed here concerns efforts by schools to reduce cues to gender stereotypes in the classroom. Recall that cues to 
gender stereotypes in the classroom can promote the belief that STEM fields are not for girls. Schools could require teachers to implement classroom changes that would foster STEM engagement for both genders. Changing classroom environments that convey masculine stereotypes about computer science (through objects and decorations) to be more neutral can increase women's interest and anticipated performance in that course (Cheryan et al., 2009; Cheryan, Meltzoff, \& Kim, 2011). Taken together, teachers of STEM courses should be mindful of the decorations within their classroom, such as science fiction or video game posters that might further perpetuate stereotypes that these subjects are more for men.

\section{Conclusion}

In this chapter, we described the problem of the hidden classroom - how subtle and sometimes implicit gender stereotypes can derail young children, and girls in particular, from developing and pursuing STEM related interests. In doing so, we have summarized current research on the development of gender stereotypes about STEM. Furthermore, we have identified potential consequences resulting from such biases. Finally, we described several theory-based interventions that caregivers and educators can implement to either change children's gender stereotypes, or to buffer children from negative effects, such as reduction of engagement and performance in STEM.

As of yet, few researchers have sought to implement these types of interventions with the goal of increasing young girls' pursuit of STEM. We are hopeful that others will see opportunity for more partnerships between educators and researchers centered around the development and implementation of successful classroom and home-based interventions. We believe these types of partnerships can provide benefits to educators by allowing them to assess the effects of existing programs to increase STEM engagement, and potentially improve upon them using 
psychological theory. Researchers can benefit as well, as these types of partnerships allow them to test theoretical predictions in a more ecologically valid environment.

Other critical areas for investigation involve further examination of the formation of implicit math-gender stereotypes, the relationship between implicit bias and behavior, and potential methods of changing implicit math-gender stereotypes. Much of the work examining gender stereotypes about math has focused on explicit bias, which might result in the underreporting of these stereotypes. Furthermore, little work has examined implicit and explicit stereotypes simultaneously, or how these stereotypes might independently predict behavior (Cvencek et al., 2011). Future work should consider examining math-gender stereotypes using both implicit and explicit measures in order to get a fuller understanding of their trajectory, as well as a clearer conceptualization of their behavioral consequences.

In conclusion, while women's underrepresentation in STEM is an ongoing problem of pressing importance, we are hopeful that the development of successful age-based and theorybased interventions will result in improved outcomes for young girls in STEM. Educators and parents play an important role in shaping children's career choices; by becoming more aware of the "hidden classroom", and how stereotypes are reinforced, they can move toward a more inclusive and encouraging environment for young girls. With more coordinated involvement from researchers, educators, and caregivers, we hope these interventions will help to remove an important barrier keeping young girls from entering STEM careers, allowing them to flourish in this globally critical domain. 


\section{References}

Ambady, N., Paik, S. K., Steele, J., Owen-Smith, A., \& Mitchell, J. P. (2004). Deflecting negative self-relevant stereotype activation: The effects of individuation. Journal Of Experimental Social Psychology, 40, 401-408. doi:10.1016/j.jesp.2003.08.003

Ambady, N., Shih, M., Kim, A., \& Pittinsky, T. L. (2001). Stereotype susceptibility in children: Effects of identity activation on quantitative performance. Psychological Science, 12, 385-390. doi:10.1111/1467-9280.00371

Baron, A. S. (2015). Constraints on the development of implicit intergroup attitudes. Child Development Perspectives, 9, 50-54. doi:10.1111/cdep.12105

Baron, A. S., \& Banaji, M. R. (2006). The development of implicit attitudes: Evidence of race evaluations from ages 6 and 10 and adulthood. Psychological Science, 17, 53-58. doi:10.1111/j.1467-9280.2005.01664.x

Beghetto, R. A. (2007). Factors associated with middle and secondary students' perceived science competence. Journal of Research in Science Teaching, 44, 800-814. doi:10.1002/tea.20166

Beilock, S. L., Rydell, R. J., \& McConnell, A. R. (2007). Stereotype threat and working memory: Mechanisms, alleviation, and spillover. Journal of Experimental Psychology: General, 136, 256-276. doi:10.1037/0096-3445.136.2.256

Beilock, S. L., Gunderson, E. A., Ramirez, G., \& Levine, S. C. (2010). Female teachers' math anxiety affects girls' math achievement. Proceedings of the National Academy of Sciences, 107, 1860-1863. doi:10.1073/pnas.0910967107

Berkowitz, T., Schaeffer, M. W., Maloney, E. A., Peterson, L., Gregor, C., Levine, S. C., Beilock, S. L. (2015). Math at home adds up to achievement in school. Science, 350, 196198. 
Bian, L., Leslie, S. J., \& Cimpian, A. (2017). Gender stereotypes about intellectual ability emerge early and influence children's interests. Science, 355, 389-391. doi: $10.1126 /$ science.aah6524

Block, K., Gonzalez, A.M., Choi, C. J. X., Wong, Z. C., \& Baron, A.S. (under review). Malleability of children's implicit gender stereotypes and self-concept.

Bottia, M. C., Stearns, E., Mickelson, R. A., Moller, S., \& Parker, A. D. (2015). The relationships among high school STEM learning experiences and students' intent to declare and declaration of a STEM major in college. Teachers College Record, 117, 1-46.

Cao, J., \& Banaji, M. R. (2016). The base rate principle and the fairness principle in social judgment. Proceedings of The National Academy of Sciences, 113, 7475-7480. doi:10.1073/pnas. 1524268113

Ceci, S. J., \& Williams, W. M. (2011). Understanding current causes of women's underrepresentation in science. Proceedings of the National Academy of Sciences, 108, 3157-3162. doi:10.1073/pnas.1014871108

Cheryan, S., Plaut, V. C., Davies, P. G., \& Steele, C. M. (2009). Ambient belonging: How stereotypical cues impact gender participation in computer science. Journal of Personality and Social Psychology, 97, 1045-1060. doi:10.1037/a0016239

Cheryan, S., Master, A., \& Meltzoff, A. N. (2015). Cultural stereotypes as gatekeepers: Increasing girls' interest in computer science and engineering by diversifying stereotypes. Frontiers in Psychology, 6, 49. doi: 10.3389/fpsyg.2015.00049

Cheryan, S., Meltzoff, A. N., \& Kim, S. (2011). Classrooms matter: The design of virtual classrooms influences gender disparities in computer science classes. Computers \& Education, 57, 1825-1835. doi:10.1016/j.compedu.2011.02.004

Cheryan, S., Plaut, V. C., Handron, C., \& Hudson, L. (2013). The stereotypical computer 
scientist: Gendered media representations as a barrier to inclusion for women. Sex Roles, 69, 58-71. doi:10.1007/s11199-013-0296-x

College Board (2016). 2016 College-Bound Seniors: Total Group Profile. Retrieved from: https://secure-media.collegeboard.org/digitalServices/pdf/sat/total-group-2016.pdf

Common Core Standards Initiative (2016). Common Core Standards for Mathematics. Retrieved from: http://www.corestandards.org/wp-content/uploads/Math_Standards1.pdf

Crowley, K., Callanan, M.A., Tenenbaum, H.R., \& Allen, E. (2001). Parents explain more often to boys than to girls during shared scientific thinking. Psychological Science, 12, 258261.

Cvencek, D., Kapur, M., \& Meltzoff, A. N. (2015) Math achievement, stereotypes, and math self-concept among elementary-school students in Singapore. Learning and Instruction, 39, $1-10$.

Cvencek, D., Meltzoff, A. N., \& Greenwald, A. G. (2011). Math-gender stereotypes in elementary school children. Child Development, 82, 766-779. doi:10.1111/j.1467 8624.2010.01529.x

Cvencek, D., Meltzoff, A. N., \& Kapur, M. (2014). Cognitive consistency and math-gender stereotypes in Singaporean children. Journal of Experimental Child Psychology, 117, 7391. doi:10.1016/j.jecp.2013.07.018

Danaher, K., \& Crandall, C. S. (2008). Stereotype threat in applied settings re-examined. Journal of Applied Social Psychology, 38, 1639-1655. doi:10.1111/j.1559-1816.2008.00362.x

Davies, P. G., Spencer, S. J., Quinn, D. M., \& Gerhardstein, R. (2002). Consuming images: How television commercials that elicit stereotype threat can restrain women academically and professionally. Personality and Social Psychology Bulletin, 28, 1615-1628. 
doi:10.1177/014616702237644

de Cohen, C. C. and Deterding, N. (2009), Widening the net: National estimates of gender disparities in engineering. Journal of Engineering Education, 98, 211-226. doi:10.1002/j.2168-9830.2009.tb01020.x

del Río, M. F., \& Strasser, K. (2013). Preschool children's beliefs about gender differences in academic skills. Sex Roles, 68, 231-238.

Dunham, Y., Baron, A. S., \& Carey, S. (2011). Consequences of 'minimal' group affiliations in children. Child Development, 82, 793-811. doi:10.1111/j.1467-8624.2011.01577.x

Eagly, A. H., \& Steffens, V. J. (1984). Gender stereotypes stem from the distribution of women and men into social roles. Journal of Personality and Social Psychology, 46, 735-754. doi:10.1037/0022-3514.46.4.735

Eccles, J. S. (2011). Understanding women's achievement choices: Looking back and looking forward. Psychology of Women Quarterly, 35, 510-516. doi:10.1177/0361684311414829

Eccles, J. S., Adler, T. F., Futterman, R., Goff, S. B., Kaczala, C. M., Meece, J. L., \& Midgley, C. (1983). Expectancies, values, and academic behaviors. In J. T. Spence (Ed.), Achievement and achievement motivation (pp. 75-146). San Francisco, CA: W. H. Freeman.

Eccles, J. S., Adler, T. F., \& Meece, J. L. (1984). Sex differences in achievement: A test of alternate theories. Journal of Personality and Social Psychology, 46(1), 26-43. doi:10.1037/0022-3514.46.1.26

Eccles, J. S., \& Jacobs, J. E. (1986). Social forces shape math attitudes and performance. Signs, 11, 367-380. doi:10.1086/494229

Eccles, J. S., \& Wang, M. (2016). What motivates females and males to pursue careers in mathematics and science? International Journal of Behavioral Development, 40, 100 
106. doi:10.1177/0165025415616201

Economics and Statistics Administration (2017). STEM Jobs: 2017 Update. Retrieved from: http://www.esa.doc.gov/reports/stem-jobs-2017-update

Fong, A., \& Finkelstein, N. (2014). Math placement: The importance of getting it right for all students. Research Brief. WestEd.

Galdi, S., Cadinu, M., \& Tomasetto, C. (2014). The roots of stereotype threat: When automatic associations disrupt girls' math performance. Child Development, 85, 250-263. doi:10.1111/cdev.12128

Gonzalez, A. M., Dunlop, W. \& Baron, A. S. (2017). Malleability of implicit associations across development. Developmental Science, 20, 1-13. doi:10.1111/desc.12481

Gonzalez, A. M., Steele, J.R. \& Baron, A. S. (2017). Reducing children's implicit racial bias through exposure to positive outgroup exemplars. Child Development, 88, 123-130. doi:10.1111/cdev.12582

Greenwald, A. G., Poehlman, T. A., Uhlmann, E. L., \& Banaji, M. R. (2009). Understanding and using the Implicit Association Test: III. Meta-analysis of predictive validity. Journal of Personality and Social Psychology, 97, 17-41. doi:10.1037/a0015575

Gunderson, E. A., Ramirez, G., Levine, S. C., \& Beilock, S. L. (2012). The role of parents and teachers in the development of gender-related math attitudes. Sex Roles, 66, 153-166. doi:10.1007/s 11199-011-9996-2

Johns, M., Inzlicht, M., \& Schmader, T. (2008). Stereotype threat and executive resource depletion: Examining the influence of emotion regulation. Journal of Experimental Psychology: General, 137, 691-705. doi:10.1037/a0013834

Keller, C. (2001). Effect of teachers' stereotyping on students' stereotyping of mathematics as a male domain. The Journal of Social Psychology, 141, 165-173. 
doi:10.1080/00224540109600544

Kiefer, A. K., \& Sekaquaptewa, D. (2007). Implicit stereotypes, gender identification, and math-related outcomes: A prospective study of female college students. Psychological Science, 18, 13-18. doi:10.1111/j.1467-9280.2007.01841.x

Lummis, M., \& Stevenson, H. W. (1990). Gender differences in beliefs and achievement: A cross-cultural study. Developmental Psychology, 26, 254-263. doi:10.1037/0012 1649.26.2.254

Maloney, E. A., Ramirez, G., Gunderson, E. A., Levine, S. C., \& Beilock, S. L. (2015). Intergenerational effects of parents' math anxiety on children's math achievement and anxiety. Psychological Science, 26, 1480-1488. doi:10.1177/0956797615592630

Master, A., Cheryan, S., \& Meltzoff, A. N. (2016). Computing whether she belongs: Stereotypes undermine girls' interest and sense of belonging in computer science. Journal of Educational Psychology, 108, 424-437. doi:10.1037/edu0000061

Master, A., Cheryan, S., \& Meltzoff, A. N. (2017). Social group membership increases STEM engagement among preschoolers. Developmental Psychology, 53, 201-209.

Master, A., Cheryan, S., Moscatelli, A., \& Meltzoff, A. N. (2017). Programming experience promotes higher STEM motivation among first-grade girls. Journal of Experimental Child Psychology, 160, 92-106. doi:10.1016/j.jecp.2017.03.013

McKenney, S., \& Voogt, J. (2010). Technology and young children: How 4-7 year olds perceive their own use of computers. Computers in Human Behavior, 26, 656-664. doi:10.1016/j.chb.2010.01.002

Mullis, I. V. S., Martin, M. O., Foy, P., Arora, A., (2012). TIMSS 2011 International Results in Mathematics. Chestnut Hill, MA: International Association for the Evaluation of Educational Achievement (IEA). 
Muzzatti, B., \& Agnoli, F. (2007). Gender and mathematics: Attitudes and stereotype threat susceptibility in Italian children. Developmental Psychology, 43, 747-759. doi:10.1037/0012-1649.43.3.747

National Research Council (2012). A Framework for K-12 Science Education: Practices, Crosscutting Concepts, and Core Ideas. Washington, DC: The National Academies Press.

National Science Foundation (2014). Science and Engineering Indicators 2014. (NSB document no. 14-01). Arlington VA: National Science Foundation.

National Science Foundation. (2017). Women, Minorities, and Persons with Disabilities in Science and Engineering: 2017 Special Report. (NSF document no. 17-310). Arlington, VA: National Science Foundation.

Nürnberger, M., Nerb, J., Schmitz, F., Keller, J., \& Sütterlin, S. (2016). Implicit gender stereotypes and essentialist beliefs predict preservice teachers' tracking recommendations. Journal of Experimental Education, 84(1), 152-174. doi:10.1080/00220973.2015.1027807

Passolunghi, M. C., Rueda Ferreira, T. I., \& Tomasetto, C. (2014). Math-gender stereotypes and math-related beliefs in childhood and early adolescence. Learning and Individual Differences, 34, 3470-76. doi:10.1016/j.lindif.2014.05.005

Parsons, J. E., Adler, T. F., \& Kaczala, C. M. (1982). Socialization of achievement attitudes and beliefs: Parental influences. Child Development, 53, 310-321. doi:10.2307/1128973

Raabe, T. \& Beelmann, A. (2011). Development of racial, ethnic, and national prejudice in childhood and adolescence: A multinational meta-analysis of age differences. Child Development, 82, 1715-1737.

Régner, I., Steele, J. R., Ambady, N., Thinus-Blanc, C., \& Huguet, P. (2014). Our future 
scientists: A review of stereotype threat in girls from early elementary school to middle school. Revue Internationale de Psychologie Sociale, 27, 13-51.

Schmader, T., \& Johns, M. (2003). Converging evidence that stereotype threat reduces working memory capacity. Journal of Personality and Social Psychology, 85, 440 452. doi:10.1037/0022-3514.85.3.440

Schmader, T., Johns, M. \& Barquissau, M. (2004). The costs of accepting gender differences: The role of stereotype endorsement in women's experience in the math domain. Sex Roles, 50, 835-850.

Schmader, T., Johns, M., \& Forbes, C. (2008). An integrated process model of stereotype threat effects on performance. Psychological Review, 115, 336-356. doi:10.1037/0033295X.115.2.336

Schmader, T., Forbes, C. E., Zhang, S., \& Mendes, W. B. (2009). A metacognitive perspective on the cognitive deficits experienced in intellectually threatening environments. Personality and Social Psychology Bulletin, 35, 584-596. doi:10.1177/0146167208330450

Smith, S. L., Choueiti, M., Prescott, A. \& Pieper, K. (2012). Career Selection: Role of Parent's Profession, Mass Media and Personal Choice. An Executive Report. Geena Davis Institute on Gender in Media.

Spencer, S. J., Steele, C. M., \& Quinn, D. M. (1999). Stereotype threat and women's math performance. Journal of Experimental Social Psychology, 35, 4-28. doi:10.1006/jesp.1998.1373

Statistics Canada (2011). Education in Canada: Attainment, field of study and location of study. (NHS publication No. 99-012-X2011001.) Ottawa: Statistics Canada.

Stearns, E., Bottía, M. C., Davalos, E., Mickelson, R. A., Moller, S., \& Valentino, L. (2016). 
Demographic characteristics of high school math and science teachers and girls' success in STEM. Social Problems, 63, 87-110. doi:10.1093/socpro/spv027

Steffens, M. C., Jelenec, P., \& Noack, P. (2010). On the leaky math pipeline: Comparing implicit math-gender stereotypes and math withdrawal in female and male children and adolescents. Journal of Educational Psychology, 102, 947-963. doi:10.1037/a0019920

Stricker, L. J., \& Ward, W. C. (2004). Stereotype threat, inquiring about test takers' ethnicity and gender, and standardized test performance. Journal of Applied Social Psychology, 34, 665-693. doi:10.1111/j.1559-1816.2004.tb02564.x

Supekar, K., Iuculano, T., Chen, L., \& Menon, V. (2015). Remediation of childhood math anxiety and associated neural circuits through cognitive training. Journal of Neuroscience, 35, 12574-12583.

Tiedemann, J. (2000). Parents' gender stereotypes and teachers' beliefs as predictors of children's concept of their mathematical ability in elementary school. Journal of Educational Psychology, 92, 144-151. doi:10.1037/0022-0663.92.1.144

Tomasetto, C., Alparone, F. R., \& Cadinu, M. (2011). Girls' math performance under stereotype threat: the moderating role of mothers' gender stereotypes. Developmental Psychology, 47, 943-949. doi:10.1037/a0024047

Valla, J. M., \& Williams, W. M. (2012). Increasing achievement and higher-education representation of underrepresented groups in science, technology, engineering, and mathematics fields: A review of current K-12 intervention programs. Journal of Women and Minorities in Science and Engineering, 18, 21-53.

doi:10.1615/JWomenMInorScienEng.2012002908 PMID:22942637. 